\section{La extensión universitaria y la universidad latinoamericana: hacia un nuevo "orden de anticipación" a 100 años de la revuelta estudiantil de Córdoba}

Agustín Cano Menoni

Universidad de la República, Uruguay.

acano@pim.edu.uy
A 100 años de la Reforma Universitaria de 1918 /

Perspectivas

RECEPCIÓN: 29/06/17

ACEPTACIÓN FINAL: 24/09/17

\section{Resumen}

En vísperas del centenario de la revuelta estudiantil de Córdoba de 1918, se presenta una buena oportunidad para reflexionar sobre la relación entre la extensión universitaria y el movimiento reformista latinoamericano. En este artículo se procura comprender las características que el extensionismo, cuyo origen es europeo, adquirió en América Latina al ser asumido y resignificado por el movimiento reformista de comienzos del siglo XX. Desde esa base, se procura también entender los efectos que sobre la extensión han tenido los procesos de contrarreforma neoliberal de la universidad de fines del siglo XX. Finalmente, se dará cuenta de algunas derivas actuales de la extensión universitaria en América Latina que podrían aportar a la construcción de un nuevo programa de reforma que vuelva a proyectar, para nuestro tiempo, los ideales del Movimiento Reformista.

Palabras clave

- Extensión universitaria

- Reforma universitaria

- Universidad latinoamericana

\section{Resumo}

Nas vésperas do centenário da revolta estudantil de Córdoba de 1918 , apresenta-se uma boa oportunidade para refletir sobre a relação entre a extensão universitária e o movimento reformista latinoamericano. Neste artigo se procura compreender as características que o extensionismo, de origem europeia, adquiriu na América Latina ao ser assumido e ressignificado pelo movimento reformista do começo do século XX. Finalmente se relatarão algumas trajeetórias atuais da extensão universitária na América Latina que podem contribuir para a construçãode um novo programa de reforma que volte a projetar os ideais do Movimento Reformista para o nosso tempo.

Palavras-chave

- Extensão universitária

- Reforma universitária

- Universidade latinoamericana

\section{Para citación de este artículo}

Cano Menoni, A. (2017). La extensión universitaria y la Universidad Latinoamericana: hacia un nuevo "orden de anticipación" a 100 años de la revuelta estudiantil de Córdoba. Revista $+E$ versión en línea, 7(7), 6-23. Santa Fe, Argentina: Ediciones UNL. 


\section{Introducción ${ }^{1}$}

La revuelta de los estudiantes de la Universidad Nacional de Córdoba de 1918 constituye el hito principal del movimiento de Reforma Universitaria que se desarrolló a lo largo y ancho de América Latina a comienzos del siglo XX. Se trató de un movimiento estudiantil que, lejos de limitarse al ámbito universitario, proyectó su programa y desplegó su acción hacia el conjunto de la vida política y cultural de los países latinoamericanos, articulándose con las luchas sociales y políticas propias del contexto de la primera posguerra mundial (Tünnermann, 2008). La importancia histórica del movimiento reformista se hace evidente en el juicio de uno de sus estudiosos, Dardo Cúneo (1988), quien le atribuye una importancia similar a la de los movimientos independentistas de comienzos del siglo XIX y al de las corrientes continentales del modernismo literario de fines del siglo XIX, como parte de la genealogía de afirmación identitaria y cultural latinoamericana.

Esta cualidad del movimiento, la de trascender la arena universitaria y desarrollar una preocupación doble por democratizar tanto la universidad como la sociedad, aportó un marco idóneo para que la extensión universitaria (originaria de Europa) arraigara en el movimiento reformista, al punto de constituir uno de los elementos principales de su programa. En este marco, la extensión, lejos de reproducir las experiencias europeas, fue resignificada, politizada y diversificada al calor del movimiento estudiantil y sus articulaciones con los movimientos sociales y las luchas políticas del continente. Así, emergieron diferentes modelos y concepciones de extensión, con diferentes desarrollos y niveles de institucionalización según contextos nacionales e históricos. Pero, ante todo, esta multiplicidad confluyó en la constitución de un ethos de la universidad Latinoamericana que tiene a la extensión como un componente principal.

Las celebraciones del centenario de la revuelta estudiantil de Córdoba presentan una buena oportunidad para reflexionar sobre la relación entre la extensión universitaria y el movimiento reformista. De este modo, en este artículo se procura comprender las características que el extensionismo adquirió en América Latina al ser asumido y resignificado por el movimiento reformista; entender los efectos que sobre la extensión tuvieron los procesos de "contrareforma universitaria" (López Segrera, 2008) de fines del siglo XX (o más precisamente, lo que podríamos llamar la concepción extensionista de la contrareforma); e intentar reflexionar sobre los desafíos de la extensión universitaria crítica en la actualidad.
1) El presente artículo retoma contenidos elaborados por el autor para la tesis doctoral "La extensión universitaria en la UNAM (1920-2015). Un análisis político-pedagógico" (UNAM, 2017). 


\section{Antecedentes de Córdoba: la extensión universitaria} más allá del "dieciochismo fundacional"

"[La Universidad deberá] promover y difundir la Educación del pueblo, buscando el engrandecimiento nacional, por medio de la educación de todas las clases sociales." Resoluciones del I Congreso Internacional de Estudiantes Americanos, Montevideo, 1908 (citado por Quiroga, 2001:2)

Para comprender el proceso de arraigo y desarrollo de la extensión en América Latina es necesario entender al movimiento reformista en su constitución internacional previa a los sucesos de Córdoba. En efecto, el extensionismo latinoamericano se fraguó en la síntesis realizada de la recepción del extensionismo europeo (culturalista y obrerista), con las características de la circunstancia latinoamericana y el pensamiento arielista ${ }^{2}$ en torno al cual se articulaban, desde el liberalismo hacia la izquierda, los estudiantes reformistas. Esto, desde una década antes de la revuelta estudiantil de Córdoba de 1918 (Van-Aken, 1990; Moraga, 2014; Biagini, 2006). Si Deodoro Roca escribió en el célebre Manifiesto Liminar: "estamos viviendo una hora americana", fue porque la verdadera significación de Córdoba era que coronaba una década de "hora americana" intensamente experimentada por las redes estudiantiles, principalmente conosureñas (Chile, Argentina y Uruguay) (Biagini, 2006). El ideario y la experiencia de la extensión universitaria y las universidades populares europeas (originadas a partir del university extension movement de Cambridge y Oxford de la década de 1870) tuvieron amplia difusión en los medios estudiantiles latinoamericanos. Las fuentes y vías para ello fueron múltiples y se intensificaron con las corrientes migratorias en la Primera Guerra Mundial. Pero entre esta diversidad de vías de transmisión hay una figura descollante por su ascendencia intelectual y su compromiso con la extensión universitaria: don Rafael Altamira. El célebre profesor de la Universidad de Oviedo era un referente destacado de la extensión universitaria en su país luego de que su Universidad comenzara a desarrollarla en el año 1898. Altamira fue además un activo difusor del extensionismo "modelo Oviedo" por las principales capitales de América Latina durante su gira americana de 1909. Su influencia en los estudiantes latinoamericanos está documentada. $Y$ en gran medida las características de ese extensionismo oviedista (culturalista, obrerista, basado en la metodología de conferencias en centros obreros) se transmitieron a las primeras experiencias extensionistas de los estudiantes reformistas.

López señala entre los antecedentes extensionistas previos a

\section{Córdoba}

"la tesis doctoral de Miró Quesada sobre 'La nacionalización del derecho y la extensión universitaria' presentada en la Facultad de Jurisprudencia de la Universidad Nacional Mayor de San Marcos, publicada en Lima en 1911 o, en el caso de la Argentina, a principios del siglo XX y antes de la Reforma, las conferencias sobre extensión universitaria de 1907 y 1908 publicadas en 1909 por Christmann y Crespo en La Plata." (2012:21)

Precisamente, en la Universidad de la Plata se iniciaron actividades de extensión ya en 1905:

"y en 1907, Joaquín V. González, como Presidente de esa universidad, inaugura las Conferencias de Extensión Universitaria y señala la importancia de '...la incorporación con carácter legal de la extensión universitaria, esto es, la de una nueva facultad destinada a crear y difundir las relaciones de la enseñanza propia de sus aulas con la sociedad ambiente... de tal manera que lo que... hasta ahora había sido una labor voluntaria, espontánea, de las corporaciones docentes, como en Oxford, Cambridge, Harvard, Pensilvania, Columbia, y otras, aquí se recogía su experiencia ya bastante completa y sistematizada y se convertía resueltamente en una función permanente' (Joaquín González en Calderari, 2002)." (Fernández, 2007:186-187)

En tanto, en México, en 1910 se incluyó a la extensión universitaria en la ley que fundó la Universidad Nacional y desde 1912 funcionó la Universidad Popular Mexicana, que realizaba conferencias, cursos, excursiones, etc., en locales propios y de asociaciones obreras. Mientras que en Uruguay, según reseña Pablo Carlevaro:

"La Asociación de Estudiantes de Medicina se fundó en 1915, y no bien se fundó, junto con la Asociación de los estudiantes de Agronomía, tomaban la ruta de la línea del tren que iba de Montevideo a Las Piedras. Iban los estudiantes
1900 y dedicada "A la juventud de América") tuvo una gran influencia en el movimiento estudiantil reformista. 
Al calor del movimiento de reforma universitaria, sus diversas expresiones, sus diferentes articulaciones con los procesos políticos y sociales del continente por un lado, y con las nuevas corrientes pedagógicas por otro, se fueron forjando las diferentes tradiciones de la extensión universitaria de matriz reformista.

y hablaban con los tipos que estaban en las estaciones de ferrocarril. Antiguamente, cuando las estaciones de ferrocarril funcionaban, eran un ámbito social. Bajaban en las estaciones y hablaban con los que estaba ahí sobre enfermedades, etc." (Entrevista personal, 29 de octubre de 2014)

Antes, el I Congreso Americano de Estudiantes realizado en Montevideo en 1908 había propuesto la creación de consultorios jurídicos gratuitos y señalado la necesidad de "acercarse a los obreros a través de conferencias públicas [todo lo cual podría] adscribirse a un programa embrionario de extensión universitaria" (Markarián y otros, 2008:58). E incluyó entre sus resoluciones el epígrafe que inicia este capítulo. ${ }^{3}$

En este proceso, la extensión fue, para el movimiento reformista naciente, un programa de transformación universitaria y un espacio de reunión, organización y politización.

\section{Características del extensionismo reformista}

"Cuando cierto falsísimo y vulgarizado concepto de la educación, que la imagina subordinada exclusivamente al fin utilitario, se empeña en mutilar, por medio de ese utilitarismo y de una especialización prematura, la integridad natural de los espíritus, y anhela proscribir de la enseñanza todo elemento desinteresado e ideal, no repara suficientemente en el peligro de preparar para el porvenir espíritus estrechos, incapaces de considerar más que el único aspecto de la realidad con que estén inmediatamente en contacto." (Rodó, 1976:9)

Al calor del movimiento de reforma universitaria, sus diversas expresiones, sus diferentes articulaciones con los procesos políticos y sociales del continente por un lado, y con las nuevas corrientes pedagógicas por otro, se fueron forjando las diferentes tradiciones de la extensión universitaria de matriz reformista. Entre ellas se puede distinguir una corriente de la extensión preocupada fundamentalmente por lograr una formación crítica y humanista de los estudiantes, vinculando su formación con las realidades más dolorosas de su medio social de pertenencia, complementando a su vez la enseñanza disciplinaria con contenidos de cultura general y formación política. En efecto, tanto como la preocupación social y política por vincular a la universidad con la suerte general de la sociedad, y en particular con los sectores excluidos de la educación superior, también forma parte de las motivaciones originarias de la extensión universitaria la preocupación por mejorar la formación de los estudiantes universitarios. Ángel Rama, en un discurso pronunciado en la II Conferencia Latinoamericana de Difusión Cultural y Extensión de Universitaria de la Unión de Universidades de América Latina (UDUAL) en 1972, daba cuenta de esta doble motivación originaria de la extensión en los siguientes términos:
3) Como han señalado los estudiosos de este evento (Van Aken, 1990; Markarián y otros, 2008), no se debe atribuir a los estudiantes del Congreso
Americano de 1908 la radicalidad política que habría de adquirir, tiempo y agua bajo el puente después, el movimiento estudiantil latinoamericano.
El perfil ideológico de los estudiantes era más bien liberal democrático, y desde dicha concepción formularon e impulsaron un programa que en mu- chos aspectos sería retomado y resignificado por las generaciones siguientes. 
"Como es sabido, estos servicios [los de extensión universitaria] son recientes en las universidades latinoamericanas; han aparecido en las últimas décadas respondiendo a un afán de corregir las visibles insuficiencias de sus institutos universitarios. Por eso su primer objetivo fue la población universitaria, concretamente los estudiantes que, a pesar de las reformas de comienzo de siglo, siguieron apresados dentro de la compartimentación de especialidades generadas por el modelo universitario positivista. Proveerlos de una visión cultural más variada y rica, compensando las estrecheces del exceso de especialización, fue el cometido central de estos servicios (...). La creación de la extensión universitaria correspondió también a otra insuficiencia, pero ésta no interna sino externa. El estrecho radio social que cubría la Universidad, limitándose prácticamente al adiestramiento técnico de los jóvenes de una clase social, la burguesía, en sus estratos alto y medio, e incorporando progresivamente dentro del proceso de democratización lenta del siglo a la baja burguesía, concluyó transformándola en un organismo elitista y clasista. Se manifestaba ausente de preocupación por ese resto de la sociedad, que era su inmensa mayoría". (1972:167)

A su vez, se puede reconocer otra tradición de la extensión cuyo énfasis estuvo puesto en dirigir la difusión de la cultura y el conocimiento universitario hacia la atención a los grandes problemas nacionales. Desde problemas de salud (que ameritaban campañas de prevención y educación de corte higienista) de analfabetismo (en cuya respuesta se estructuraron las míticas misiones pedagógicas en México, Uruguay y otros países), o problemas de tipo urbano, productivo, etc. (Soler, 2015; Gamboa, 2007). Así, por ejemplo, en un texto de 1928, sostenía Carlos Quijano, figura destacada del reformismo uruguayo:

"Por su carencia de finalidad científica, la Universidad vive desconectada con la realidad nacional. Lo está también por su hermetismo de casta. No estudia ningún problema nacional a fondo; no es capaz tampoco de ilustrar a las grandes masas sobre esos problemas. (...) ¿No será necesario que la Facultad de Arquitectura hiciera oír su voz sobre el problema de la urbanización de Montevideo? ¿No sería útil que la Facultad de Ingeniería trazara un plan general de vialidad del país? ¿No convendría que la Facultad de Derecho o la de Ciencias Económicas a crearse, tuvieran un Instituto de Investigaciones, como en Harvard o como en Londres, para establecer de una manera precisa las fuerzas productoras del país, su desarrollo, etc.? Y dígase todavía, ¿no sería de desear que sobre todas esas cuestiones que a título de ejemplo hemos citado y sobre muchas otras más, semejantes, la Universidad ilustrara a las grandes masas, abriendo cursos públicos como en las Universidades europeas que hemos conocido, manteniendo, sin esperar a que la iniciativa venga de afuera, una organización de conferencias, etc.? Intensidad, extensión, realismo, ¿no podría ser ésta la fórmula de la Reforma?”. (1988:262)

Y, finalmente, gran importancia tuvieron también las perspectivas extensionistas más preocupadas por colaborar con los procesos de transformación y emancipación social, ligando a la universidad y a los movimientos estudiantiles a las luchas de los sectores populares a través de diferentes iniciativas. En un principio, la metodología era la de las conferencias en locales obreros sobre temas culturales y científicos, o legales y políticos. La siguiente noticia, publicada en el periódico Solidaridad de la Federación Obrera Regional Uruguaya (FORU) en junio de 1920, ilustra esta matriz extensionista:

"Hermosa iniciativa de los estudiantes del Centro Ariel. Por intermedio de un delegado este Centro estudiantil el Consejo Federal de la FORU ha sido informado del propósito, altamente humano, de un núcleo de jóvenes estudiantes, de hacer extensiva al pueblo trabajador, por todos los medios a su alcance, la cultura intelectual que se adquiere a base de los estudios universitarios que por desgracia no son asequibles hoy por hoy a las clases laboriosas. Por ello organizarán varios cursos de extensión universitaria en forma de conversaciones familiares en diversos locales obreros. Solicitado por los jóvenes estudiantes el concurso de este Consejo Federal, a objeto de emplear en mayor grado la campaña cultural que están decididos a llevar a cabo, se ha puesto de inmediato a disposición de los compañeros del Centro Ariel, entendiendo que al obrar así, interpreta felizmente los principios de la organización obrera y tiende a realizar en parte los fines por ella perseguidos, ya que acrecentando la capacidad de los trabajadores les será más fácil a éstos conquistar su emancipación integral. En breve se anunciarán los días y locales en que se dictarán los distintos cursos sobre temas del más vivo interés para el proletariado, esperando que éste sabrá responder al llamado de sus compañeros los obreros intelectuales que vienen a compartir con ellos el pan del espíritu que es la ciencia para que ella sirva a todos los seres humanos y no se convierta en monopolio de una casta". (FORU, 1920)

La nota de prensa reproduce también la carta enviada por el Centro Ariel a la FORU. En su contenido, se evidencian los rasgos de este 
extensionismo obrerista, algunas de sus influencias intelectuales (como José Ingenieros) y una temprana preocupación por superar la metodología de ellas conferencias, que denota la mención que se hace a "conversaciones familiares". La nota, dirigida al Secretariado de la FORU, dice:

"Compañero: El Centro de Estudiantes 'Ariel' tiene el agrado de hacerle saber que, en una de sus últimas reuniones, la Comisión Directiva ha resuelto organizar una serie de 'conversaciones familiares' en diversos locales obreros de la Capital que versarán sobre asuntos de ciencia, letras, artes, cuestiones de actualidad, etc. que estarán a cargo de estudiantes de las distintas facultades. Oportunamente pondremos en su conocimiento el día, tema, local, etc. en que se iniciarán aquellas conversaciones. El Centro Ariel considera que, junto a los hombres que quieren deben ir los hombres que saben el conocimiento y la orientación mental, la emoción y los pensamientos desinteresados junto al brazo una voluntad firme y superior. Entiende que la colaboración de los hombres especializados en las disciplinas mentales debe hacerse efectiva en la obra social; que el trabajo de la inteligencia que crea, debe aliarse cordialmente al trabajo manual que realiza. Cree, con Ingenieros, que todas nuestras aspiraciones encaminada a asegurar la libre expansión del individuo dentro de la sociedad, se resumen en un concepto 'Solidaridad' tienden a un resultado 'Justicia'. Tal nuestro propósito, para cuya realización esperamos vuestra colaboración, a fin de ponernos de acuerdo sobre la mejor forma de realizarlo. Saludo a Ud. atte., Carlos Quijano (Presidente) y Walter Pérez (Secretario)". (1920)

En efecto, en esta iniciativa del Centro Ariel, similar por lo demás a las que por la misma época se desarrollaban en México, Argentina, Chile y Perú "entre otros países" constituye un ejemplo del movimiento que intentaban los estudiantes reformistas, de "exclaustración popular de la cultura". Ese mismo año se publicó la obra La Universidad del Porvenir de José Ingenieros, en la cual destacaba:

"No es menos importante la necesidad de imprimir a cada Universidad una dirección ideológica concordante con las necesidades y los ideales del medio social en que funciona; es forzoso reconocer que ello dependerá del grado de exclaustración que alcancen los estudios universitarios, tomando contacto con el pueblo, sirviendo sus intereses, reflejando sus aspiraciones, comprendiendo sus problemas vitales". (1920:82)

En tanto, cabe destacar, dentro del extensionismo de perfil obrerista, al mayor exponente de esta tradición: las universidades populares desarrolladas en varios países, con particular relevancia en México, Perú y Argentina, a comienzos del siglo pasado, y en Uruguay a partir de la década de 1930.
Para resumir los rasgos de este extensionismo reformista originario, cabe señalar que las experiencias desarrolladas en este período inicial fueron consideradas luego por diferentes autores como "asistencialistas", "culturalistas" o de un ocasional vanguardismo político (Bralich, 2007; Tünnermann, 2000). Jorge Bralich, por ejemplo, afirma:

"La extensión universitaria ha sido encarada desde dos perspectivas: la 'culturalista', desde la cual se percibía a los destinatarios de la extensión como seres pasivos que debían recibir una cultura 'superior' elaborada por los sectores universitarios y otra perspectiva distinta liberadora- desde la cual se procuraba un acercamiento al destinatario de la extensión para desarrollar en él su propia capacidad de crear cultura, para realizar conjuntamente con el extensionista universitario, una interpretación de la realidad y una transformación de la misma. La primera perspectiva ha sido la más común en los orígenes del movimiento de extensión hasta bastante avanzado el siglo XX — por la década de los 50 aproximadamente - en tanto la otra perspectiva se desarrolló a partir de entonces vinculada a las concepciones de ciertas formas de trabajo y acción política”. (2007:34)

No le faltan argumentos a esta crítica. Sin embargo, para situarla en sus justos términos, es importante considerar la observación que, analizando el caso de Uruguay, realiza Pablo Carlevaro con referencia a esa etapa primigenia de la extensión:

"Se trataba de una actitud paternalista y de una forma expositiva de hacer la extensión que no dejaba de tener, sin embargo, su significado y su valor ético. Concretamente, en el campo de la salud, la Asociación de Estudiantes de Medicina se encargó de realizar actividades de extensión durante muchísimos años, como una tradición gremial, en ambientes populares, tales como las escuelas nocturnas, los sindicatos obreros, las instituciones sociales y deportivas de la comunidad, etcétera. Esto fue durante no menos de cuarenta años, entre 1915 y 1955. Caritativa o paternalista, la práctica se hizo con una constancia y un desinterés inusuales". (1986:9)

Avanzando en el análisis, Carlevaro traza un interesante paralelismo y sostiene que este extensionismo originario "remedaba, en la relación con la gente, lo que era la relación del aula entre profesores y estudiantes. Iban a dar clases, a hablar de las enfermedades más frecuentes, con sentido de prevención, pero no había la participación de la gente en el proceso". (Entrevista personal, 29 de octubre de 2014)

Y además de la constancia y el desinterés es posible rastrear posicionamientos críticos dentro del temprano pensamiento extensionista latinoamericano. Así, por ejemplo, el Centro de Estudiantes de Derecho de la Universidad de Buenos Aires, al 


\section{G6}

\section{Desde la gramática positivista se constituyó toda una importante tradición de la extensión basada, en términos generales, en el modelo de la transferencia tecnológica.}

inaugurar los cursos de extensión universitaria de 1920, expresaba: "La miseria y el dolor son, sin dudas, poderosos factores insurreccionales, pero sólo constituyen fuerzas primarias de arranque; no bastan para realizar un movimiento provechoso y duradero. En cambio, la reacción resultante de toda injusticia, lo que vale decir resultante de un conocimiento más denso del derecho, acelera la evolución, y se alza contra las iniquidades que violan la armonía social. (...) La nueva generación aspira a ser cada vez menos categoría, para hacer cada vez más función, dentro del cuerpo social. No queremos imponer una verdad substantiva. No queremos conducir. Queremos que cada uno tenga capacidad para concurrir con esfuerzo consciente a preparar el resurgimiento fecundo y dinámico de la humanidad reconciliada”. (citado en Cúneo, 1988:25)

Esta cita nos pone en camino de señalar, finalmente, uno de los componentes que habrán de distinguir al extensionismo de América Latina: la tradición de la "extensión crítica" de vocación transformadora de la sociedad en un sentido popular y democratizante. Efectivamente, un primer hito en la conformación de esta tradición está dado por la revuelta de Córdoba, y el salto cualitativo ideológico y político que significó para el movimiento estudiantil latinoamericano. Un segundo hito habrá de suceder algunos años después, con la emergencia de un nuevo ciclo de luchas sociales en el continente, y el surgimiento de la elaboración pedagógica del movimiento de educación popular encabezado por Paulo Freire. Pero este tema escapa al alcance de este artículo.

\section{Dos genealogías, múltiples extensionismos}

Hasta aquí se ha desarrollado la tradición reformista de la extensión, cuya deriva contiene expresiones de tipo culturalistas y las concepciones llamadas "críticas", resaltando que los elementos que se articularon en la formulación freireriana como una crítica a la invasión cultural estaban presentes, a su modo, también en algunas expresiones extensionistas de la primeras décadas del siglo XX.
Esta tradición reformista, como hemos fundamentado, surge principalmente de la genealogía europea de la extensión universitaria, cuyo origen está en la university extension inglesa, en particular los modelos extensionistas de las universidades de Oxford y Cambridge. La concepción general que inspiraba estas acciones se podría sintetizar en una persona: el Cardenal John Henry Newman, uno de los intelectuales que tempranamente impugnó las corrientes utilitaristas que comenzaban a surgir y transformar modelos y concepciones de la universidad y el conocimiento. Para él la difusión del conocimiento y la cultura era una de las misiones principales de la universidad. Como señala Casanova:

"Para Newman (1986:xxxvii) la universidad debe ser el lugar de enseñanza del conocimiento universal con un objeto intelectual y no moral, ocupándose para tal efecto de la difusión del conocimiento, más que de su progreso. El fin de la universidad es la 'educación liberal', entendida como aquélla en la cual, el conocimiento se imparte por su propio fin, más allá de sus implicaciones profesionales y utilitarias". (2015:50)

En tal sentido, el propósito de la educación superior implica, antes que la formación profesional para acceder al trabajo, o la dedicación a la investigación científica, el cultivo de la inteligencia por sí misma, lo que no significa, según Newman, la simple búsqueda de

"los hábitos de los gentlemen ( ), sino de la fuerza, la firmeza, la comprensión y versatilidad del intelecto (Newman, 1986:xlii). La educación liberal que se proponía implica por tanto, un distanciamiento ante los valores entonces vigentes de la sociedad industrial en cuanto a la formación profesional y, por otro lado, un cuestionamiento a la excesivamente especializada en la investigación (Wittrock, 1991)”. (52)

Estas concepciones orientaron la labor extensionista de las principales universidades inglesas. Luego, como fue señalado, estas experiencias se resignificaron y diversificaron de la mano 
de las universidades populares que surgieron en varios países europeos. No caben dudas de que esta línea del extensionismo reformista (perteneciente a la genealogía del extensionismo difusionista, culturalista, obrerista de la University Extension inglesa y las universidades populares europeas) es característica y constitutiva del ethos de la universidad latinoamericana. No obstante, no es la única tradición extensionista presente, sino que existe también otra genealogía extensionista de gran influencia en el continente, respecto a la cual la tradición reformista en ocasiones se articuló o traslapó, y en otras tensionó o antagonizó. Tomando la observación de Larrosa (2003), quien señala que los discursos sobre la educación en la modernidad se han construido en lo fundamental en torno a dos articulaciones discursivas (y sus respectivas lógicas): el par ciencia-tecnología, propio de la tradición positivista, y el par teoría-práctica de la tradición crítica, es posible identificar con cierta nitidez la presencia de estas dos tradiciones entre las principales gramáticas desde las cuales se construyeron los discursos, lógicas y racionalidades en torno a la extensión universitaria, desde su origen en la universidad latinoamericana a comienzos del siglo XX hasta el presente. ${ }^{5}$ Ya se han presentado las características principales de la tradición crítica, basada en el modelo de la educación popular freireriana (pero con formulaciones y experiencias anteriores a Freire), para el cual el extensionista es un "intelectual orgánico" (en la acepción gramsciana) o un "intelectual transformador" (en la del pedagogo Henry Giroux). Se reseñarán ahora, brevemente, las características de la tradición que, con Larrosa, llamamos como "positivista". Antes de hacerlo, vale aclarar que ambas tradiciones, la positivista y la culturalista (dentro de la cual se ubicaría la tradición crítica), y sus respectivos horizontes ético-políticos (modernización-progreso-desarrollo, emancipación-liberación), con frecuencia se han formulado como opuestas. No obstante, también se articularon en algunas coyunturas del proceso histórico latinoamericano a través de la contradicción modernización-conservadurismo.
Desde la gramática positivista se constituyó toda una importante tradición de la extensión basada, en términos generales, en el modelo de la transferencia tecnológica. Se podría señalar que para este modelo la extensión universitaria es un engranaje en el circuito ciencia-innovación-aplicación. ${ }^{6}$ En ese continuo, el lugar de la ciencia aparece ligado a la función de investigación (sus laboratorios y sus científicos), y el lugar de la "aplicación" es el que corresponde a la extensión y a los extensionistas, que serían algo así como "traductores" o "transmisores" de los adelantos del conocimiento científico en diversos campos de la sociedad. La tradición positivista transferencista ha tenido un desarrollo mayor en determinadas áreas de conocimiento, ligadas a las ingenierías, las ciencias y en particular las ciencias agrarias. Tommasino (1994) destaca la influencia que la corriente denominada "difusión de innovaciones" (cuyo principal exponente es el sociólogo Everett Rogers) ha tenido en las agencias estatales de extensión rural así como en la formación de los profesionales universitarios del área agraria. Señala Tommasino que la "difusión de innovaciones" vino de la mano de la "Revolución Verde", constituyéndose en su dispositivo de difusión extensionista. La Revolución Verde fue el proceso de expansión de la producción agrícola norteamericana, que inmediatamente se formuló como programa exportado desde los Estados Unidos para la modernización y el desarrollo rural en los países del tercer mundo. Junto a este propósito explícito, la propuesta dio viabilidad a la dinámica de acumulación capitalista de la época al generar espacios de comercialización de los productos derivados de la industria mecánica, química y biológica norteamericana, que habían perdido mercados con la terminación de la guerra a mediados de la década de 1940 del siglo XX. Basado en las ideas de Rostow acerca del desarrollo económico, ${ }^{7}$ el extensionismo positivista transferencista originario concebía que la superación de las condiciones críticas de la sociedad rural (pobreza, problemas de salud, de acceso a la educación, de vivienda, etc.) dependía de la capacidad de los "sectores atrasados"
5) En otro trabajo, en la línea de lo planteado en este capítulo, hemos distinguido entre dos modelos extensionistas: "el difusionista transferencista" y el de la "extensión crítica", de acuerdo con los siguientes criterios: "cómo se define y qué lugar se asigna, en cada modelo, al interlocutor social de las experiencias de extensión, si se promueve o no cierta precisión conceptual de la extensión, y cómo se define (explícitamente o por la negativa) a la extensión y sus horizontes pedagó- gicos y ético-políticos" (Tommasino y Cano, 2016:12)

6) Si bien el modelo de la transferencia tecnológica está asociado al área de conocimiento científico-tecnológico, y en particular al papel de la extensión universitaria en la modernización productiva (generalmente desde el modelo del "triángulo de Sábato"), no menos importante es su expresión en otras áreas. De este modo, aquí se agrupa en la misma denominación también la importante tradición asis- tencial de la extensión universitaria. En esta vertiente, lo que se transfiere son "tecnologías del yo" (en el sentido estudiado por Foucault, 1990), normas de higiene y conducta, junto a la eventual resolución técnica de determinado problema de salud. Por tal motivo, a los efectos de este análisis, se agrupan estas diferentes corrientes de la extensión, algunas ligadas a la modernización productiva, otras a la asistencia y promoción de la salud, en un mismo modelo basado en la transferencia de saberes y tecnologías desde la universidad hacia lo social, con el fin de lograr cambios en los comportamientos, hábitos o procedimientos de un determinado grupo social, respecto a un determinado tipo de actividad (productiva, social, sanitaria, alimentaria, etc.) (Cano, 2015).

7) Picos (2014) documenta la relevancia del pensamiento de Rostow en la extensión rural de origen norteamericano y difusión generalizada en América Latina. 
para adoptar nuevas ideas. Es decir, para pasar a ser actores innovadores capaces de adoptar las tecnologías de insumo que modifican sus sistemas de producción. ${ }^{8}$ Al decir de Rogers y Shoemarker:

"A largo plazo, pudiéramos desear que los cambios principales fueran espontáneos y no dirigidos. Cuando la gente vaya adquiriendo más experiencia técnica y sutileza en el diagnóstico de sus necesidades el cambio selectivo ocurrirá con más rapidez y se efectuará de modo más eficiente. En lo futuro, suponemos que el agente, innecesario ya para diagnosticar necesidades y promover innovaciones que las satisfagan, podrá atender requerimientos de innovaciones de sus clientes. Hoy, los esfuerzos se centran en el cambio dirigido; en lo futuro, se dará importancia a facilitar los cambios inmanente y selectivo, si los promotores de cambio logran mejorar la capacidad y aptitud de sus clientes para analizar necesidades". (1974:10-11)

Están delineadas aquí las responsabilidades principales del extensionista como "promotor de innovaciones" productoras del desarrollo (y dinamizadoras de la industria norteamericana). Gabriel Picos (2014) destaca las diferencias y relaciones entre el extensionismo rural de carácter estatal, impulsado por Estados Unidos desde la década de 1950, y el extensionismo universitario, cuya genealogía —desde su origen europeo a su asimilación reformista latinoamericana - ha sido ya analizada en las páginas precedentes. Señala que, en ocasiones, ambas tradiciones se han imbricado, sobre todo en contextos en que los Estados logran incorporar la universidad, a través de la extensión, a sus programas de tipo modernizador desarrollista. De este modo, la distinción entre ambas tradiciones no siempre ha resultado clara $y$, en cualquier caso, el extensionismo rural norteamericano (el que criticó Freire en “¿Extensión o comunicación?”) se imbricó fuertemente con el extensionismo universitario hasta el presente. Pero a su vez es necesario considerar otro aspecto, que le da una vuelta de tuerca a la genealogía de la tradición extensionista que aquí se analiza: la tradición extensionista norteamericana, surgida en un período más o menos contemporáneo al extensionismo europeo. El extensionismo norteamericano se organizó tempranamente como dispositivo universitario de contribución a la modernización y mejora de los procesos tecnológicos y productivos agrícolas, a partir de estrategias situadas cercanas a los colonos y productores rurales. Es decir que el extensionismo rural de mediados del siglo XX (que articuló la teoría económica de Rostow y el modelo de la Revolución Verde, y que se expandió por el tercer mundo como parte de la estrategia internacional económica y política contrainsurgente norteamericana) forma parte a su vez de esta genealogía de un extensionismo iniciada a mediados del siglo XIX.

Roberto Rodríguez destaca, dentro de este extensionismo norteamericano temprano, la "idea de Wisconsin" generada a partir de la Merril Act de 1862, la cual abrió la "posibilidad de que los colegios y universidades recibieran tierras a cambio de adscribir los propósitos de agricultura y el acta de mecánica (propósitos de modernización agrícola y expansión industrial)" (2009:4).

En el marco del Land grant movement, Estados Unidos generó facilidades de este tipo para las universidades en diferentes Estados. Rodríguez señala que aunque "la university extension propiamente dicha se funda en EE. UU. en 1907, con perfil de agentes rurales, radio, educación por correspondencia y a distancia", la "idea de Wisconsin" constituye un antecedente extensionista (5). Y es, por lo demás, un antecedente de la tradición que en materia de vinculación social universitaria habría de desarrollarse con más fuerza en Estados Unidos, desde el modelo de Wisconsin, pasando por el de Columbia, hasta el modelo de "la triple hélice" en las últimas décadas del siglo XX.

Al analizar la historia de la extensión universitaria en América Latina, la presencia de esta tradición extensionista estadounidense es menos perceptible, o está de algún modo latente a principios del siglo pasado, fruto de la preponderancia que a todas luces tuvo el extensionismo reformista de origen europeo y resignificación ideológica latinoamericana. No obstante, su presencia se puede rastrear también a comienzos del siglo XX. Desde mediados del siglo pasado en adelante, con la consolidación del pensamiento desarrollista, el extensionismo rural de la Revolución Verde, la transformación de la universidad estadounidense en la posguerra en el sentido de su corporativización y vínculo orgánico con la industria, la globalización económica y la emergencia de paradigmas como la "sociedad de conocimiento" y el modelo universitario de "la triple hélice", la tradición positivista-transferencista cobrará fuerza y se expresará en diferentes formulaciones teórico-metodológicas.

\section{Contrarreforma universitaria y destitución del sentido crítico de la extensión \\ Como señala Casanova:}

"A partir de la posguerra la educación superior estadounidense consolida su presencia internacional y logra extenderse como un modelo fundado en la articulación de una serie de
8) Tecnologías de insumo son aquellas producidas por la industria mecánica, biológica y química (maquinaria agrícola, semillas híbridas, fertilizantes químicos y agrotóxicos biocidas) (Tommasino, 1994). 


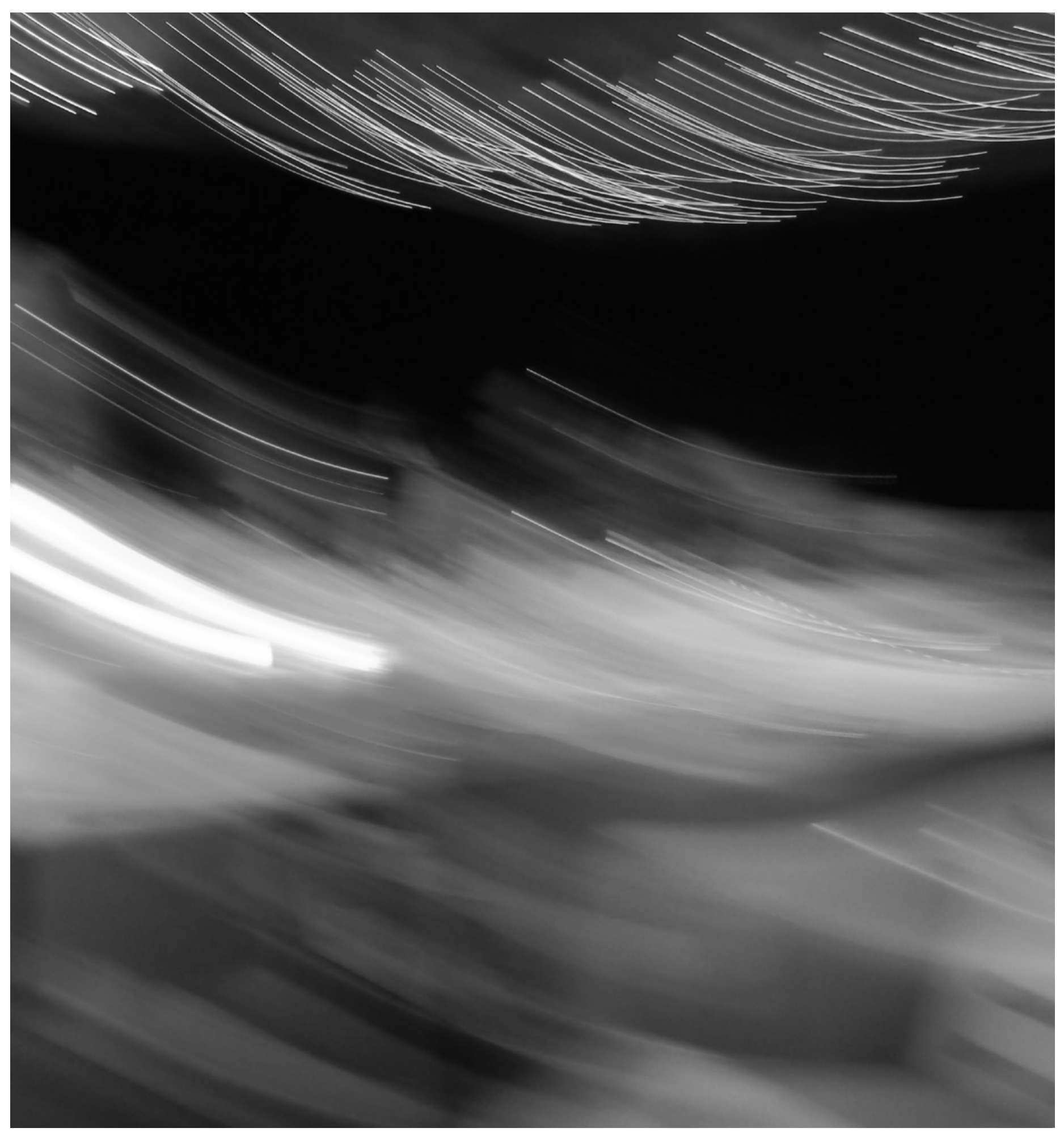

() Cecilia lucci 
factores entre los que destacan: a) la atención masiva a la demanda social y un consecuente proceso de expansión, b) el proceso de diversificación en todos sus niveles, c) la estructura departamental de su organización, d) la existencia de mecanismos externos de supervisión, e) el estímulo diferenciado a las funciones de investigación, f) el impulso a la competencia entre las diversas instituciones y g) el predominio del mercado en la orientación del conjunto universitario y sus instituciones" (2004:200)

En tanto, haciendo referencia a Gumport, subraya que en este contexto ocurre

"un desplazamiento de la idea legitimadora de educación superior como una institución social hacia otra idea que la define como un complejo aparato industrial. Gumport alude a la tensión entre la concepción tradicional que asigna a la educación superior la responsabilidad de conservar un amplio rango de funciones sociales y culturales, del cultivo del ciudadano en términos de formar el carácter de los individuos y los hábitos del pensamiento; y otra visión, que concibe a la universidad como un modelo corporativo inserto en un mercado competitivo para producir y vender bienes o servicios, y que participa en el desarrollo económico a través del entrenamiento de fuerza de trabajo y de investigación productiva. Es en esta línea que tienen cabida los análisis que dan cuenta de las capacidades 'adaptativas' de la universidad contemporánea”. (205)

López Segrera destaca la profundidad del proceso de transformación como alteración del ideario latinoamericano de universidad, al punto de señalar la existencia de una "contrarreforma universitaria" de signo neoliberal. Sus rasgos serían: la diversificación de las instituciones de educación superior (IES); las "alianzas estratégicas entre agencias internacionales y autoridades gubernamentales"; el aumento de la oferta privada y el surgimiento de nuevos proveedores; las políticas de clasificación de los profesores vía incentivos definidos por indicadores de productividad; las reformas curriculares orientadas a acortar las carreras, generar grados intermedios y flexibilizar planes de estudios; la importación de modelos pedagógicos basados en el modelo de competencias; el predominio de las TIC y el aumento de modalidades de "universidad virtual tutoría remota, certificación del conocimiento y de habilidades, reciclaje de capacidades" (2008:272-273).
Precisamente, la principal característica de las reformas neoliberales de la educación superior radica en la subsunción de la universidad a la economía de mercado globalizado de acuerdo con los requerimientos de la división internacional del trabajo. Carnoy y Rothen constatan la estrecha relación que existe entre las reformas universitarias contemporáneas y la reestructuración económica del capitalismo globalizado:

"En los términos del mercado de trabajo, los gobiernos están simultáneamente bajo presión para atraer capital extranjero, y esto significa proporcionar un eficiente suministro de mano de obra calificada. Esto se traduce en una presión para aumentar el nivel medio de educación de la fuerza laboral". $(2002: 5)^{9}$

Estos autores señalan la tensión intrasistémica entre la necesidad de aumentar la formación de la fuerza laboral y a la vez recortar el gasto público educativo, lo que se traduce en el fomento de determinados tipos de formaciones específicas (en general de perfil tecnológico y corta duración), en detrimento de otras. Por su parte, en el mismo sentido, Ordorika y Lloyd advierten que, en el actual contexto de globalización capitalista, las instituciones de educación superior

"desempeñan una doble función: la creación de conocimiento y la provisión de capacidad técnica para el mercado global. Sin embargo, las decisiones sobre los tipos y usos del conocimiento, así como del perfil ideal del trabajador, en gran medida se determinan en el exterior, y más tarde son internalizadas a través de políticas nacionales e institucionales (Rhoads y Torres, 2006)". $(2014: 130)$

Estos rasgos habrían de tener una fuerte influencia en la resignificación de la extensión universitaria. Se suele pensar que el proyecto universitario neoliberal niega la función de extensión y busca más bien su eliminación por considerarla politizada y anacrónica. Puede que así sea si nos limitamos a la consideración de las tradiciones críticas del extensionismo. Pero esta línea de razonamiento impide observar un hecho incontrastable: el programa neoconservador de contrarreforma universitaria sí tiene un proyecto extensionista, entendiendo por tal a una concepción y un modelo de relación universidad-sociedad como función transversal a la investigación y la enseñanza. En efecto, el proceso de subsunción universitaria al capital en el sentido del capitalismo académico (Slaughter y Leslie, 1999) ha abarcado tanto los fines y funciones de las universidades como sus 
modos de financiamiento y administración, formatos escolares, contenidos curriculares y modelos pedagógicos. Ha implicado también una progresiva sustitución de las tradiciones reformistas de la extensión por una creciente prioridad hacia las políticas de vinculación universidad-empresa.

Así, a partir de las décadas de 1980 y 1990, el paradigma de la vinculación universidad-empresa se vio fortalecido e impulsado a nivel de los gobiernos nacionales, en un contexto en el que determinados organismos internacionales ligados a la globalización económica emitieron documentos y recomendaciones para la transformación de la educación superior. La International Council of Educational Development (ICED), el Banco Mundial (BM), la Organización para Cooperación y el Desarrollo Económico (OCDE) y el Banco Interamericano de Desarrollo (BID), son algunos de los principales organismos encargados de formular e impulsar el programa neoliberal de reforma de la educación superior a fines del siglo XX (González, 2010). Entre las recomendaciones realizadas por estos organismos se encuentra la de que las universidades deben "diversificar" sus fuentes de financiamiento a través de la venta de servicios a empresas.

Esta concepción ideológica respecto de la universidad, presentada usualmente bajo la forma aséptica de los diagnósticos tecnocráticos y las respuestas razonables, tuvo también su correlato en destacados teóricos de la educación superior, quienes, en mayor o menor grado, se sumaron al discurso único economicista y posibilista de la mercantilización educativa como camino a la pertinencia y la autosustentabilidad. Es el caso de Burton Clark $(1998,2004)$, y su propuesta de la entreprenurial university, que contó con el auspicio de la OCDE y la Comunidad Europea (EC y OECD, 2012).

La entreprenurial university de Clark asume con criterio pragmático a la globalización económica como un hecho dado y propone proyectar la universidad al mercado como criterio de pertinencia y como estrategia de diversificación del financiamiento. A su modo, la propuesta de Clark parte del extendido diagnóstico de la crisis por disfuncionalidad de la universidad moderna, y plantea resolver dicha crisis a partir de: a) revitalizar la promesa de empleablidad de sus egresados a partir de regular su oferta formativa a los requerimientos de dinámicas económicas localizadas y su perfil de egreso al ideal de emprendedor dúctil y competitivo; b) ser "autosustentable" económicamente a partir del cobro de matrícula, cuotas y derechos de exámenes, así como por la venta de servicios a empresas; c) responder a los desafíos de "la sociedad del conocimiento" y al "desarrollo local" a través de la incorporación de capacidades empresariales a los medios sociales y productivos en los que se inserta por medio de la transferencia tecnológica y la incubación o formación de empresas; y d) modificar su organización administrativa de acuerdo al paradigma de "la nueva gestión pública" (Cano Menoni, 2015).

En la misma línea de Clark, el otrora desarrollista José Joaquín Brunner plantea:

"Al entrar al siglo XXI, ¿cuál es entonces el desafío que la región debe enfrentar? Dicho en breve: avanzar aceleradamente por el camino del crecimiento para asegurar a cohesión social $y$, al mismo tiempo, incorporarse a la nueva economía basada en conocimientos, a la sociedad de la información y la cultura global”. (2007:221)

Y agrega:

"las universidades miran hacia adentro más que hacia afuera, se aíslan de los contextos de aplicación y utilización, rehuyen la valoración de sus actividades por los mercados y prefieren depender de los escasos y muchas veces oscilantes recursos del Estado antes que diversificar sus propias fuentes de financiamiento". (224-225)

El paradigma del crecimiento económico como camino per se al desarrollo, y la resignificación pro mercado de la vinculación universitaria como criterio de pertinencia y como vía de financiamiento, aparecen, con el cambio de siglo, como componente del sentido común del pensamiento sobre la universidad.

Como parte de estos procesos se dio la emergencia y progresiva hegemonía del modelo de la vinculación universidad-empresa (erigido sobre la genealogía del extensionismo transferencistautilitario de origen norteamericano), el cual produce una transformación del tipo de lo que Mollis (2003) define como "alteración". Es decir: una transformación que trasciende los aspectos meramente organizativos y funcionales e implica también la afectación del sentido constitutivo del quehacer extensionista, los sentidos ético-políticos y los fundamentos filosóficos desde los cuales se concibe la relación universidadsociedad a través de la extensión. La extensión pasará a estar, en esta concepción, diagramada por una lógica mercantil en la que la universidad encuentra una oportunidad financiera y las empresas una posibilidad de acceso a innovaciones tecnológicas 
y mano de obra cualificada que le reporten ventajas comparativas. Se da así un conflicto a nivel del ethos de la universidad latinoamericana, entre dos imaginarios contrapuestos: el forjado por el movimiento reformista, con Córdoba como hito, y el de contrarreforma neoliberal de la universidad de fin de siglo XX y comienzos del XXI. En el primero de estos imaginarios —ligado a los sentidos que Ordorika (2013) atribuye a su idea de "Universidad constructora de Estado" - ${ }^{10}$ se apoyaron históricamente las tradiciones extensionistas latinoamericanas de perfil reformista durante casi todo el siglo XX. En el segundo de ellos —que podríamos resumir en el nuevo "ideal del yo universitario" que configura el modelo de la World Class University, ${ }^{11}$ atento a los rankings, forjándose en relaciones de competencia desde la racionalidad del productivismo académico y la concepción de la universidad como engranaje de la "economía del conocimiento"se apoyan en la actualidad el paradigma de la vinculación universidad-empresa y muchos de los discursos reformistas y modernizadores en boga. En el primero, la extensión se funda y sustancia en razones de solidaridad, caridad, democratización, desarrollo y/o justicia social (por nombrar algunos de los sentidos históricos asignados a la extensión, con mayor o menor niveles de politización según coyunturas, actores y circunstancias). En el segundo, la extensión —devenida vinculación con la empresase funda y sustancia en razones de competencia, productividad y ventajas comparativas.

\section{A modo de cierre: cinco cauces para la extensión crítica en el siglo XXI}

Como señala Ordorika:

"En el contexto de un mercado internacional, jerarquizado y de una percepción hegemónica de que constituye una universidad exitosa en la sociedad contemporánea, el reto para las universidades periféricas es la preservación y recreación de la diversidad de tradiciones y responsabilidades a partir de un eje fundamental: un compromiso con la sociedad en su sentido más amplio. A partir de esta noción es posible construir una variedad amplia de alternativas fundadas en las distintas tradiciones y en las diversas condiciones históricas. La ampliación de la valoración societal de la institución universitaria constituye un elemento crucial para articular la fuerza necesaria para desbordar el reduccionismo productivista y de mercado como fin último de la educación superior. En la articulación con los problemas, demandas y expectativas de la sociedad en su conjunto radica la posibilidad de ir más allá de los estrechos límites del modelo hegemónico para expandir el horizonte de desarrollo de las universidades públicas". (2007:16)

En procura de aportar en dicha dirección, a continuación se intenta una primera aproximación a los principales cauces teóricos y experienciales que es posible encontrar en torno a la extensión universitaria en nuestro continente. Por cierto, se trata de un panorama incompleto pero suficiente para ejemplificar la vitalidad de los caminos alternativos a la despolitización conservadora y la contrarreforma empresarial de la extensión universitaria latinoamericana. En este sentido, distinguimos cinco cauces de la extensión crítica en el continente, de gran potencial pedagógico y político.

1) La extensión crítica integrada al currículo universitario. Una de las características más notorias del desarrollo institucional de la extensión universitaria es que, por diferentes razones, ocurrió disociado —en general— de los procesos de formación curricular de los estudiantes universitarios. Esta disociación es aún más notoria respecto a los programas de posgrado, con lo cual el par investigación-posgrado pocas veces se articula con programas de extensión. Sin embargo, la dimensión pedagógica de la extensión, su potencial formativo humanista e integral de los estudiantes universitarios, ha sido un elemento nodal en la tradición extensionista latinoamericana (Rama, 1972; Carlevaro, 1973; Tünnermann, 2000). No son pocas las universidades en las que se promueve en la actualidad estrategias de integración curricular
10) Imanol Ordorika, luego de analizar la peculiar historia de las universidades latinoamericanas, las define como "Universidades Constructoras de Estado" (UCE): "[La UCE] encarna el mito creacionista de los proyectos nacionales en las esferas intelectual, social y política, el legado y la promesa del afán por escolarizar a la población y el avance nacional. La presencia de la UCE concretiza la saga nacional que simboliza el orgullo nacional, las oportunidades y el desarrollo mediante la educación superior. Es una institución que nutre las aspiraciones intelectuales y personales de la nación y sus habitantes, sus movimientos sociales, revoluciones y restauraciones. Describir estas complejas y con frecuencia, contradictorias instituciones, que son consideradas a la vez como templos del conocimiento, crisoles de justicia social, semilleros de la generación de conocimientos y de la protesta social, es poner a prueba los límites del Lenguaje" (2013:110).

11) La expresión worldclassuniversity

("universidad de clase mundial"), más que referir a una categoría claramente definida, proyecta un sentido general ligado a las cumbres de la estratificación de las universidades (según los modelos dominantes), y opera en el debate mundial de la educación superior como un impreciso objetivo a perseguir. Como señalan Lloyd y otros: "El término "universidades de clase mundial" o worldclassuniversities ha cobrado fuerza durante la última década, en gran parte gracias al éxito del ranking ARWU, de la Universidad de JiaoTong Shanghái, institución que tiene su propio Centro de Universidades de Clase Mundial, el cual ha organizado cuatro congresos sobre el tema desde 2005. Sin embargo, no hay consensos en torno a la definición de este término. Para la universidad china, no sólo tiene que ver con la capacidad de producción científica o de docencia, sino también con la habilidad para competir en el mercado global de la educación superior" (2011:5). 
de la extensión, concebida como parte del proceso formativo de los estudiantes, procurando también su articulación con la investigación. Una política fuertemente impulsada en este sentido se dio en la Universidad de la República, UdelaR (Uruguay) en el período 2006-2014 (Tommasino y otros, 2010). También es una referencia en este sentido el sistema universitario cubano (HicklingHudson, 2006), entre otras experiencias como las existentes en universidades mexicanas (Ejea Mendoza, 2000; Molina y otros, 2014), o en universidades argentinas (Menéndez, 2013; Castro y Oyarbide, 2015; Mato, 2013).

\section{2) Extensión e "intensión" universitaria con movimientos} sociales. La extensión universitaria se juega en un espacio de frontera entre lo universitario y lo "no universitario" (frontera que las experiencias de extensión a veces reafirman y a veces interpelan). Recuperando la tradición extensionista de las "universidades populares" o "universidades obreras", actualmente existen importantes programas que vinculan a las universidades con los movimientos sociales. ${ }^{12}$ Estos programas logran resignificar el espacio de frontera de la extensión como espacio de diálogo de saberes o "extensión en sentido contrario", según la expresión acuñada por De Sousa Santos (2006b) para describir la incorporación de la agenda y los saberes de los movimientos en las propias agendas universitarias. En la misma línea, Tatián (2013) habla de "intensión universitaria", como un proceso complementario a la extensión, y subraya la doble direccionalidad en la circulación de los saberes y objetos de estudio entre la universidad y los movimientos. Tatián plantea que en estos procesos de extensión e intensión se resignifica la propia autonomía universitaria, que pasa de ser una autonomía puramente defensiva a una "autonomía heterogénea", positiva. No se trata de renunciar a la importante función defensiva de la autonomía, ni de desconocer lo específico de la lógica académica, los saberes universitarios y sus marcos epistémicos e institucionales de enunciación. Sí se trata de abrir espacios en los que la universidad ensaye una "autonomía heterogénea" al generar programas de trabajo sistemáticos y de largo plazo con movimientos y organizaciones sociales, sustentados en la "ecología de saberes" (De Sousa Santos, 2006a). Ecología de saberes que requiere de una disposición ético-metodológica al diálogo, lo cual no implica desconocer que tanto como el diálogo existe el "conflicto de saberes" (Falero y Pérez, 2014), pero el punto de partida pasa por concebir a los movimientos como "sujetos político-pedagógicos" e "intelectuales colectivos", en ocasiones portadores de un proyecto político-educativo propio (Ouviña, 2015; Pinheiro, 2016).

No obstante la importancia de esta perspectiva, es necesario considerar la condición contrahegemónica de la extensiónintensión crítica con movimientos sociales. En la relación universidad-sociedad, que es constitutiva de la extensión en cada momento histórico, los referentes teóricos, las prioridades políticas y los sujetos que encuentran mayores condiciones de legitimidad y posiciones de fuerza para significar y disputar el sentido de la política extensionista de la universidad tienden a ser los agentes de la globalización capitalista dominante (son cada vez más, en la actualidad, las universidades públicas con proyectos, cátedras o departamentos financiados por empresas
12) Algunos ejemplos de programas de estas características se encuentran en la UdelaR de Uruguay (los programas de la Unidad de Extensión y Cooperación con Organizaciones Sociales del Servicio Central de Extensión). A su vez, el Movimiento Sin Tierra de Brasil (MST), que cuenta con sus propios programas y centros de formación, tiene relaciones estables con universidades del continente (como la Universidad de Córdoba, Argentina y la UdelaR, Uruguay). A su vez, existen ejemplos en esta línea en varias universidades del continente, tanto a nivel institucional, como desarrollados de modo autónomo por organizaciones estudiantiles y docentes. 
mineras o multinacionales de diferente tipo). La extensión, como proceso educativo universitario, se juega siempre en relación con los procesos sociopolíticos de su contexto histórico que la sobredeterminan (en el sentido de Zemelman, 2010). La perspectiva extensionista con movimientos sociales encuentra terreno más propicio para su desarrollo en los ciclos históricos de ascenso de las luchas sociales y mayor politización del conflicto social. En tales coyunturas, los movimientos populares tienen mejores condiciones para tensionar a la universidad en su compromiso. La coyuntura político-social latinoamericana de los últimos años ha presentado, en cambio, realidades en las que los movimientos sociales se encuentran en situación de dispersión y reflujo y otras en las que, luego de un ciclo ascendente de luchas antineoliberales, han sido en buena medida neutralizados por procesos políticos que Modonesi (2012) describe con la noción gramsciana de "revoluciones pasivas", con efectos de amortiguación del conflicto social y pasivización de los movimientos populares. Actualmente nos encontramos en un momento de cambio de ciclo cuya deriva histórica está abierta y presenta importantes desafíos a los movimientos del continente. Modonesi y Svampa señalan que el nuevo ciclo político que se abre tiene como principal desafío para los movimientos sociales lograr la articulación entre dos "líneas de acumulación histórica hoy desconectadas": las "luchas socioambientales" (principalmente organizadas en la resistencia contra el extractivismo) y "las luchas urbanas y sindicales", expresiones cuya

"trayectoria y espesor difieren según los países y experiencias,

[y] podrían establecer un diálogo mayor, en términos de estrategias de acción y resistencias a la restauración conservadora y de superación del progresismo pero también de diálogo en cuanto a la concepción del cambio civilizatorio y los conceptos-horizonte". (2016)

Si se concibe a los movimientos sociales no desde posturas esencialistas, sino ubicados en el propio "despliegue de sus luchas" (Castro y otros, 2015), es necesario enfocar en estas derivas a los desafíos de la construcción conjunta de extensiónintensión entre universidad y movimientos sociales.

\section{3) Incubadoras de emprendimientos asociativos y cooperativos} populares. Analizando el caso de la universidad brasilera, sostiene Renato Dagnino (2015) que el modelo universitario hegemónico en dicho país se estableció desde una concepción de la investigación formulada desde los intereses del capital y desde la racionalidad de las ciencias naturales, que "reconfiguró de arriba a abajo" a las funciones de enseñanza y extensión. Señala Dagnino que el proyecto alternativo deberá "partir de la extensión" y desde allí reformular a las demás funciones. La extensión, aquí, deberá no solo reutilizar a la "tecnociencia" sino refundarla, sobre nuevas bases, de acuerdo con el diálogo de saberes con los sectores populares y en respuesta a las necesidades de los sectores subalternos. Asimismo, indica que los dos ejes para reformular la universidad y relanzar un proyecto popular para la transformación universitaria son la extensión universitaria y la economía solidaria, y el ejemplo que mejor representa esta unión son los proyectos de incubadoras universitarias de emprendimientos cooperativos. Este tipo de programas tiene un gran potencial y un importante desarrollo en las universidades del Cono Sur, como lo evidencian Cortegoso y otros (2012), quienes sistematizan experiencias de estas características en Uruguay (UdelaR), Argentina (Universidad de Buenos Aires —UBA_ y Universidad Nacional de Mar del Plata — UNMdP_, Brasil (Universidade Federal de São Carlos -UFSCar-, Universidade Federal do Paraná —UFPR—y Universidade Federal de Rio Grande Do Sul —UFRGS—) y Paraguay (Universidad Nacional de Asunción —UNA-).

\section{4) Enfoque territorial desde programas universitarios} integrales situados. Junto a los espacios de trabajo con organizaciones sociales, resultan particularmente potentes para el desarrollo de una política extensionista transformadora los programas integrales territoriales (Carlevaro, 1998) o programas universitarios de "aula abierta" basados en el "vínculo entre formación, investigación y cooperación comunitaria" (Rodríguez y Rosen, 2016). Se trata de programas radicados territorialmente en zonas populares en el medio urbano o rural que, desde una conformación y concepción interdisciplinaria, desarrollan procesos de extensión, investigación y docencia en torno a problemáticas sociales relevantes de dichos territorios, con la participación de los sujetos y comunidades de referencia (Acosta y Bianchi, 2010; Carlevaro, 1998). Encontramos ejemplos de este tipo de programas en la UdelaR ${ }^{13}$ (Uruguay), en la Universidad de Playa Ancha (Chile), ${ }^{14}$ en la Universidad Autónoma de la Ciudad de México (UACM) ${ }^{15}$ o en la Universidad Nacional Autónoma de México (UNAM). ${ }^{16}$ En Argentina, según señala Rinesi, el desarrollo
13) Los Programas Integrales han tenido un interesante desarrollo en la UdelaR (Uruguay) a partir de antecedente del Programa APEX-Cerro (http://www.apexcerro.edu.uy/) creado a comienzo de los '90. En 2008 se creó también el Programa Integral
Metropolitano (PIM) (http://www.pim. edu.uy/). A su vez, el desarrollo de la UdelaR en el interior del país ha promovido una lógica de articulación territorial que favorece esta perspectiva extensionista.

14) Proyecto "Generación de co- nocimiento compartido: Un modelo replicable de Innovación Social para el desarrollo territorial de Playa Ancha": http://territorioplayancha.cl/)

15) Por ejemplo, el "Grupo Multidisciplinario de Investigación Comunitaria" o el "Programa de Educación
Superior para Centros de Readaptación Social" (PESCER), ambos en ciudad de México.

16) Por ejemplo, la "Unidad Académica de Estudios Regionales" en La Ciénaga, Michoacán (México). (http:// uaer.humanidades.unam.mx/). 
de universidades públicas ubicadas en diferentes partes del territorio ha favorecido una lógica de mayor compenetración entre ellas y sus entornos sociales. Rinesi señala que a estas nuevas instituciones se les plantea el desafío de, por una parte, realizarse plenamente en tanto universitas de acuerdo con una lógica de lo universal y, por otra parte, sostener la lógica de las "universidades situadas", el diálogo con las organizaciones y comunidades de su entorno (2015:108).

\section{5) La extensión en la repolitización intelectual ilustrada de la}

polis. Al analizar el caso mexicano, Carlos Monsivais reflexionaba: "En la crisis de la educación superior en las universidades públicas (crisis de recursos, de calidad formativa, de cauces vocacionales, de oportunidades laborales), la difusión cultural no es, como tanto tiempo se ha creído, un complemento de amenidad, sino el remanente comprobado de la formación humanista, descartada oficialmente en los años sesenta. Ese fue el sentido de la difusión cultural y ése debe seguir siendo, con el apoyo de la televisión y de una producción editorial cuyo destino no sea la bodega. Ante la barbarie del proyecto neoliberal, que se propone sacrificar generaciones enteras, la revitalización del humanismo es tarea de primer orden, y en la UNAM un instrumento óptimo es, repensada, reformulada, la difusión cultural”. (1990:15)

Su reflexión sigue vigente, y bien se puede generalizar al conjunto del continente. Las instituciones universitarias han jugado históricamente un importante papel en tanto constitutivas (a la vez producto y productoras) de lo que Ángel Rama definió como "la ciudad letrada" en América Latina. Es decir, la totalidad orgánica producida por la "dialéctica espacial" (Remedi, 1996) de las relaciones de saber (letrado)-poder constitutivas del proceso civilizatorio latinoamericano. "Hay un laberinto de las calles y un laberinto de los signos" (Rama, 1998:38), y ambos funcionan articulándose en la producción de símbolos, narraciones, regímenes de verdad (en la noción foucaultiana) y ordenamientos espaciales orientados a la producción y reproducción de las relaciones de poder en cada momento histórico.

El papel de los intelectuales (y de las universidades) no se puede comprender fuera de esta totalidad orgánica. Así, la extensión universitaria se puede pensar como dispositivo de desterritorialización de las demarcaciones espaciales (en los sentidos anteriormente comentados) y un movimiento democratizante de las propias relaciones de saber-poder a través del ejercicio de enunciación crítica sobre los temas de la polis. Se trata de que la universidad sirva también al espesor y alcance de los debates que suceden (o deberían suceder) en el espacio público concebido como espacio político, ejerciendo el "uso público de la razón" (en el sentido kantiano). La universidad que participa y propicia lo que Rinesi llama la "gran conversación colectiva", y pone

"sus dispositivos de investigación y crítica al servicio del desnudamiento de los mecanismos ideológicos que operan por detrás de los mensajes que recibe toda la ciudadanía de los medios de comunicación más poderosos, la de contribuir a que esa misma ciudadanía pueda ser, ella misma, sujeto activo de esos procesos de comunicación masiva, manejando con destreza técnica y profesional las herramientas que le permitan hacer oír una voz propia, autónoma y distinta de esas que le llegan de esos medios tan grandes e influyentes ( ) [y a la vez] siendo ella misma protagonista de procesos de comunicación masiva". (2015:138)

En esta perspectiva extensionista se articula la rica y centenaria tradición latinoamericana de la "difusión cultural" (con centro en las humanidades y los discursos, contenidos y saberes no utilitarios), junto con la tradición de la "divulgación de la ciencia" (igualmente cultural), y contribuyen ambos tipos de actividad a la nutrición intelectual y cultural del pensamiento y el debate público. En cauce extensionista es posible ubicar algunos de los programas de difusión cultural y divulgación de la ciencia de la UNAM o de la UdelaR, ${ }^{17}$ entre muchos otros ejemplos. Dichos programas permiten resituar el papel del universitario en tanto intelectual y contravienen la tendencia dominante en la academia contemporánea, que lo instrumentaliza en una dinámica alienante de productivismo competitivo.

A cien años de la revuelta estudiantil de Córdoba, la extensión universitaria vuelve a estar en el centro de la disputa por la idea de la universidad latinoamericana. Si, como señala Dardo Cúneo (1988), independientemente de los logros efectivamente alcanzados, el movimiento de Reforma Universitaria fue capaz de proponer un "orden de anticipación" a los problemas y conflictos de su tiempo, forjó un ideario y proyectó un programa dirigido a refundar la universidad y sus misiones en un sentido popular y

17) Por ejemplo el programa "Comprensión pública de temas de interés general". (http://www.csic.edu.uy/ renderPage/index/pageld/141) o el proyecto "Juicios Ciudadanos" (http:// www.juiciociudadano.org/). 
democrático, el desafío de la actualidad puede ser planteado en términos similares. En tiempos en los que el conocimiento y la tecnología han alcanzado una importancia inédita en las relaciones globales y en las dinámicas locales de explotación, dominación y resistencia, y en un contexto en el que la contrarreforma neoliberal de la universidad amenaza con subsumir a las universidades a las demandas del mercado mientras neutraliza a las organizaciones docentes con estímulos económicos y dispersa a los movimientos estudiantiles con la diversificación segmentada de la oferta educativa, se hace indispensables un nuevo "orden de anticipación" y un nuevo programa reformista. En ello la extensión universitaria deberá ocupar, nuevamente, un lugar principal.

\section{Referencias bibliográficas}

Acosta, B. y Bianchi, D. (2010). Programas integrales: instrumentos para la transformación universitaria. En Nordan y El Colectivo, Universidad en movimiento. Debates y memorias del X Congreso Iberoamericano de Extensión Universitaria. Montevideo: Extensión Universitaria.

Biagini, H. (2006). Redes estudiantiles en el Cono Sur (1900-1925). En Marsiske, R. (Coord.), Movimientos estudiantiles en la historia de América Latina, (III), 279-296. México: IISUE-UNAM.

Bralich, J. (2007). La extensión universitaria en el Uruguay. Antecedentes y desarrollo en la Universidad de la República desde sus inicios hasta 1996. Montevideo: UdelaR.

Brunner, J. J. (2007). La universidad latinoamericana frente al próximo milenio. En Pantoja, D. (Comp.), Antología del pensamiento latinoamericano sobre la educación, la cultura y las universidades. México: UDUAL.

Cano Menoni, A. (2015). La extensión universitaria en la transformación de la Universidad Latinoamericana del siglo XXI: disputas y desafíos. En Acosta Silva, A. et al., Los desafíos de la Universidad Pública en América Latina y el Caribe. Buenos Aires: CLACSO-Instituto Gino Germani (UBA).

Carlevaro, P. (1973). La Extensión Universitaria. Postulados del Doctor Pablo Carlevaro en la Discusión del Consejo de Facultad de Medicina. La Extensión Universitaria. Montevideo: UdelaR.

(1986). Extensión universitaria. Cuadernos de Política Universitaria, 1(1). CIPE-ASCEEP-FEUU.

(1998). Resumen informativo con perspectiva evaluativa sobre el Programa APEX-Cerro. Montevideo: APEX-UdelaR.

Carnoy, M. \& Rhoten, D. (2002). What does globalization mean for educational change? A comparative approach. Comparative Education Review. The University of Chicago Press \& Comparative and International Education Society, (46)1, 1-9. Casanova Cardiel, H. (2004). La Universidad hoy. En Casanova, H. y Lozano, C. (Eds.), Educación, universidad y sociedad: el vínculo crítico. Barcelona: Universitat de Barcelona.

(2015). Universidad y Estado. Del pensamiento del siglo XIX a la primera mitad del siglo XX. Revista Universidades (UDUAL), (65), 49-57.

Castro, J. y Oyarbide, F. (2015). Los caminos de la extensión en la Universidad Argentina. Santa Rosa: Universidad Nacional de La Pampa.
Clark, B. (1998). Creating Entrepreneurial Universities: Organisational Pathways of Transformation. New York: International Association of Universities and Elsevier Science.

(2004). Sustaining Change in Universities. Continuities in Case Studies and Concepts. London: Open University Press.

Cortegoso, A.; Sarachu, G. y Pereyra, K. (2012). Universidad y trabajo asociado. Prácticas Académicas Integrales en el Cono Sur. Montevideo: Extensión Universitaria.

Cúneo, D. (1988). La Reforma Universitaria 1918-1930. Caracas: Ayacucho. Dagnino, R. (2015). Como é a universidade de que o Brasil precisa? Avaliação, (20)2, 293-333.

Ejea Mendoza, L. T. (2000). La difusión y extensión de la cultura. En López Zárate, R.; González Cuevas, O. M. y Alvarado, M. A., Una historia de la UAM. Sus primeros 25 años, / (pp. 185-230). México: Universidad Autónoma Metropolitana. European Commission (EC) y Organisation for Economic Cooperation and Development (OECD) (2012). A Guiding Framework for Entrepreneurial Universities. Recuperado de: https://www.oecd.org/site/cfecpr/guiding-framework.htm (01/06/2017). Falero, A. y Pérez, M. (2014). Visibilizando un encuentro de saberes en el tema mapuche: aportes a partir de una de sus voces. En Encuentro de saberes: luchas populares, resistencias y educación. Revista semestral de historia, antropología y educación, (1)川.

Fernández, L. (2007). La extensión universitaria en el marco de los procesos de evaluación institucional. Análisis de casos. En Krotsch, P. y otros (Coord.), Evaluando la evaluación. Políticas universitarias, instituciones y actores en Argentina y América Latina. Buenos Aires: Prometeo Libros.

Federación Obrera Regional Uruguaya (1920). Solidaridad. Órgano de la Federación Obrera Regional Uruguaya, (junio). Montevideo.

Gamboa, J. (2007). Las misiones culturales entre 1922 y 1927. En IX Congreso Nacional de Investigación Educativa. Mérida: COMIE.

González, M. (2010). Neoliberalismo y educación superior en México. Tesis de Licenciatura no publicada. UNAM, México.

Hickling Hudson, A. (2006). La Universidad y el Intercambio Educacional: La Contribución Cubana al Desarrollo Post colonial. En Austin, R., Imperialismo Cultural en América Latina: Historiografía y Praxis (pp. 25-63). Santiago de Chile: Ediciones CECATP.

Ingenieros, J. (1920). La Universidad del porvenir. Buenos Aires: Ateneo. Larrosa, J. (2003). La experiencia y sus lenguajes. En Serie Encuentros y Seminarios. Buenos Aires: Ministerio de Educación de la República Argentina. Lloyd, M.; Ordorika, I. y Rodríguez, R. (2011). Los Rankings Internacionales de Universidades, su impacto, metodología y evolución. México: DGEI-UNAM. López Segrera, F. (2008). Tendencias de la educación superior en el mundo y en América Latina y el Caribe. Avaliação (13)2, 267-291.

López, M. (2012). Extensión Universitaria: situación actual y aportes metodológicos. Jujuy: Universidad Nacional de Jujuy.

Markarian, V.; Jung, M. y Wschebor, I. (2008). 1908: el año augural. Montevideo: Archivo General de la Universidad de la República.

Mato, D. (2013). Contribución de experiencias de vinculación social de las universidades al mejoramiento de la calidad académica y factores que limitan su desarrollo y valoración institucional. Avaliação, 1(18), 151-180. 
Menéndez, G. (Coord.) (2013). Integración docencia y extensión. Otra forma de enseñar y de aprender. Santa Fe: Ediciones UNL.

Modonesi, M. (2012). Revoluciones pasivas en América Latina. Una aproximación gramsciana a la caracterización de los gobiernos progresistas de inicio del siglo. En Thwaites Rey, M. (Ed.), El Estado en América Latina: continuidades y rupturas (pp. 139-166). Santiago de Chile: Arcis y CLACSO.

Menéndez, M. y Sosa, M. (2015). La renovada capacidad de impugnar. Luchas sociales y hegemonía progresista. Contrapunto, (7), 39-55.

Modonesi, M. y Svampa, M. (10/08/2016). Posprogresismo y horizontes emancipatorios en América Latina. La Izquierda Diario.

Molina, A.; Colorado, A.; Barradas, S. y Fowler, P. (2014). La extensión universitaria en América Latina: implicaciones y alcances. En La construcción del futuro: Ios retos de las Ciencias Sociales en México. Memorias del $4^{\circ}$ Congreso Nacional de Ciencias Sociales. México: CESMECA-UNICACH-COMECSO.

Monsiváis, C. (01/04/1990). La difusión cultural en la UNAM. Nexos, (s/n). Recuperado de: http://www.nexos.com.mx/?p=5791 (16/05/2017)

Moraga, F. (2014). Reforma desde el sur, revolución desde el norte. El Primer Congreso Internacional de Estudiantes de 1921. En Estudios de Historia Moderna y Contemporánea, (47, enero-junio), 155-195. México: IIH-UNAM.

Ordorika, I. (2007). Universidades y globalización: tendencias hegemónicas y construcción de alternativas. Educación Superior y Sociedad, 1 (12), 175-190. IESALC-UNESCO.

(2013). La universidad constructora de Estado. En Rodríguez Gómez, R. (Coord.), El siglo de la UNAM. Vertientes ideológicas y políticas del cambio institucional (pp. 108-134). México: UNAM.

Ordorika, I. y Lloyd, M. (2014). Teorías críticas del Estado y la disputa por la educación superior en la era de la globalización. Perfiles Educativos, XXXVI(145), 122-139.

Ouviña, H. (2015). Los movimientos populares como intelectuales colectivos. Contrapunto, (6), 79-102.

Picos, G. (2014). Extensión rural: genealogía y construcción de referencias filosóficas hacia nuevas prácticas en el Uruguay. Montevideo: Extensión Universitaria.

Pinheiro, L. (2016). Educación, resistencia y movimientos sociales: la praxis educativo política de los Sin Tierra y de los Zapatistas. México: UNAM.

Quijano, C. (1988 [1928]). La Reforma Universitaria y la Facultad de Derecho de Montevideo. En Cúneo, D., La Reforma Universitaria 1918-1930 (pp. 259-268). Caracas: Ayacucho.

Quiroga, L. (2001). Apuntes para la historiografía de la extensión universitaria (interacción social). Ponencia en el VI Congreso Iberoamericano de Extensión Universitaria, San Pablo.

Rama, Á. (1972). Diez tesis sobre la integración cultural en América Latina a nivel universitario. En UDUAL: Memorias de la ll Conferencia Latinoamericana de Difusión Cultural y Extensión de Universitaria de la UDUAL. México: UNAM-UDUAL. (1998). La ciudad letrada. Montevideo: Arca.

Remedi, G. (1996). Ciudad letrada: Ángel Rama y la espacialización del análisis cultural. En Moraña, M., Ángel Rama. Estudios críticos (pp. 97-123). Pittsburgh: University of Pittsburgh.

Rinesi, E. (2015). Filosofía (y) política de la Universidad. Buenos Aires: UNGS.

Rodó, J. E. (1976). Ariel. Caracas: Ayacucho.
Rodríguez, M. y Rosen, A. (2016). Abrir las aulas. Universidad y vinculación comunitaria. México: UACM.

Rodríguez, R. (2009). El significado de la extensión universitaria en el presente. Inédito.

Rogers, E. y Shoemarker, F. (1974). La Comunicación de Innovaciones: un enfoque transcultural, México-Buenos Aires: Agencia para el Desarrollo Internacional. Slaughter, S. y Leslie, L. (1999). Academic capitalism. Politics, policies, and the entreprenurial university. Baltimore: The Johns Hopkins University Press.

Soler, M. (2015). Las misiones socio pedagógicas: las de ayer, las de hoy, las de mañana. Conmemoración del $70^{\circ}$ aniversario de la iniciación de las Misiones Socio Pedagógicas en Uruguay. Montevideo: Consejo de Educación Inicial y Primaria del Uruguay.

Sousa Santos, B. de (2006a). La universidad popular de/ siglo XXI. Lima: UNMSM. (2006b). Renovar la teoría crítica y reinventar la emancipación social (encuentros en Buenos Aires). Buenos Aires: CLACSO.

Tatián, D. (2013). La invención y la herencia. Notas liminares para una universidad abierta. En // Colóquio Internacional NUPSI-USP, San Pablo.

Tommasino, H. (1994). Los Paradigmas y Modelos de Difusión de Tecnología y Desarrollo Rural. En AA. VV., Grupos y Metodología Grupal en la Lechería Uruguaya, Montevideo: Facultad de Veterinaria.

Tommasino, H. y Cano Menoni, A. (2016). Modelos de extensión universitaria en las universidades latinoamericanas en el siglo XXI: tendencias y controversias. Universidades, (67).

Tommasino, H.; Cano Menoni, A.; Castro, D.; Santos, C. y Stevenazzi, F. (2010). De la extensión a las prácticas integrales. En La extensión en la transformación de la enseñanza: los Espacios de Formación Integral. Montevideo: UdelaR. Tünnermann, C. (2000). El nuevo concepto de extensión universitaria y difusión cultural y su relación con las políticas de desarrollo cultural en América Latina. Anuario de Estudios Centroamericanos, 4.

(2008). 90 años de la Reforma Universitaria de Córdoba (1918-2008). Buenos Aires: CLACSO.

Van Aken, M. (1990). Los militantes. Una historia del movimiento estudiantil universitario uruguayo. Montevideo: Fundación de Cultura Universitaria.

Zemelman, H. (2010). Desafíos de lectura de América Latina. México: Cerezo Editores. 